\title{
Prediction of Post Total Thyroidectomy Hypocalcaemia using Perioperative Parathyroid Hormone
}

\author{
M.A.Abdel Hakim, A.M.Zidan, M.E.Abdellatif and A.O.AbdelGhaffar \\ General Surgery Dept., Faculty of Medicine, Benha Univ., Benha, Egypt \\ E-Mail: AhmedOsama22@gmail.com
}

\begin{abstract}
Thyroidectomy is one of the most common operations performed worldwide by various surgeons whether general or endocrine surgeons. The rate of complications following thyroidectomy has been progressively decreasing yet it still carries significant morbidity if preoperative preparation and patient as well as procedure selection were not optimized. The aim of this study is to evaluate the reliability of perioperative parathyroid hormone measurement to predict post-total thyroidectomy hypocalcaemia.Our study was prospective non-randomized study done from November 2018 till September 2019 in Benha university hospital, general surgery department, Benha, Egypt. The study included 50 patients having thyroid disease for whom total thyroidectomy was indicated. From the study serum calcium concentrations have been the basis of identification of post-operative hypocalcaemia however this has been replaced by PTH levels being more sensitive and specific to the early prediction of hypocalcaemia. In the study a drop in postoperative PTH levels by more than $62 \%$ compared to preoperative level giving $75 \%$ Sensitivity, $84.21 \%$ Specificity, PPV $60 \%$ and NPV $91.43 \%$. a drop in postoperative PTH levels by more than $62 \%$ may serve as a sensitive and specific indicator of hypocalcemia with high overall accuracy and this will help in selecting patients for early discharge after total thyroidectomy.
\end{abstract}

Keywords: Thyroidectomy, Hypocalcaemia, PTH levels, Complications, Prospective, Serum calcium.

\section{Introduction}

Thyroid surgery is one of the most frequently performed surgical procedures worldwide. In fact, total thyroidectomy is now widely accepted as the gold standard for the management of thyroid carcinoma and benign bilateral thyroid disease due to suspicion of cancer, symptoms of local compression, and a patient's desire for rapid and definitive treatment [1].

Currently, total thyroidectomy is considered a safe procedure when performed by experienced surgeons. The main postoperative complications are RLN palsy and hypocalcaemia [2].

By definition, transient hypocalcaemia resolves within 6 months after total thyroidectomy; its reported incidence ranges from $0.3 \%$ to $49 \%$. Permanent hypocalcaemia persists after 6 months, with an incidence ranging from $0 \%$ to $13 \%$ [3].

Transient post-thyroidectomy hypocalcaemia is self-limiting, but it could potentially be life-threatening. Hypocalcaemia symptoms are uncommon unless serum calcium level is below $8.0 \mathrm{mg} / \mathrm{dL}$ ( $2.0 \mathrm{mmol} / \mathrm{L})$ [4].

To manage postoperative hypocalcaemia, most practitioners obtain serial serum calcium measurements and respond appropriately to low levels. Oral supplementation is started with elemental calcium with or without calcitriol for immediate management of postsurgical hypoparathyroidism [5].

Several studies suggested that low postoperative parathyroid hormone (PTH) levels can predict hypocalcaemia; it can be used to tailor supplement treatment options and prevent transient hypocalcaemia [6].

Despite the different methods to evaluate and predict postoperative hypocalcaemia, there is no consensus on the role of routine calcium and/or vitamin D following thyroid surgery [6].

\section{Patients and methods}

Our study was prospective non-randomized study done from November 2018 till September 2019 in Benha university hospital, general surgery department, Benha, Egypt. The study included 50 patients having thyroid disease for whom total thyroidectomy was indicated.

\section{Inclusion criteria included}

The following patients were included in the study: Any patient in whom total thyroidectomy was indicated (e.g. Multinodular goiter with cosmetic or pressure symptoms, controlled toxic goiter). Age was more than 18 years. No previous neck or thyroid surgery.

\section{Exclusion criteria included}

The following patients were excluded from the study: Patients with hyperparathyroidism (any patients with elevated serum parathyroid hormone), Patients with malignant thyroid disease, Patients with hypercalcaemia due to any cause, Patients with hypocalcaemia due to any cause and Patients with acute or chronic kidney disease needing treatment.

\section{Preoperative workup}

patients underwent the following

1- Complete history taking:

2- Investigations:

- Laboratory investigations: General pre-operative investigations for all the patients: CBC, KFT, LFT, Bleeding profile, ECG and Thyroid function test (free T3, free T4 and TSH) to control the toxicity.

- Preoperative sample collection: Serum calcium (total and ionized). Parathyroid hormone level.

- Radiological investigations: Ultrasound examination of the neck: This was the preliminary investigation for all patients. Preparation for thyrotoxic goiter patients: carbimazol. Propranolol 
(Inderal). Preop indirect laryngoscopy to assess vocal cord mobility.

\section{Operative workup}

- Anesthesia: All patients received general anesthesia with endotracheal intubation. The patient was placed in the supine position on the operating table with the arms tucked close to the side. The operating table placed in a reverse Trendelenburg position to decrease the cervical venous pressure.

- Skin Incision and Dissection: After marking the landmarks, a transverse skin incision was made approximately two fingerbreadths above the suprasternal notch at, or parallel to, a skin crease.

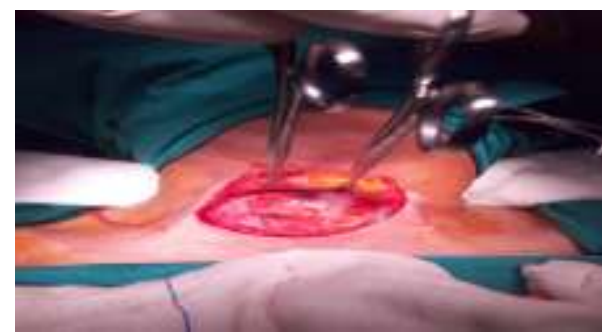

Fig (1) Elevation of superior flab.

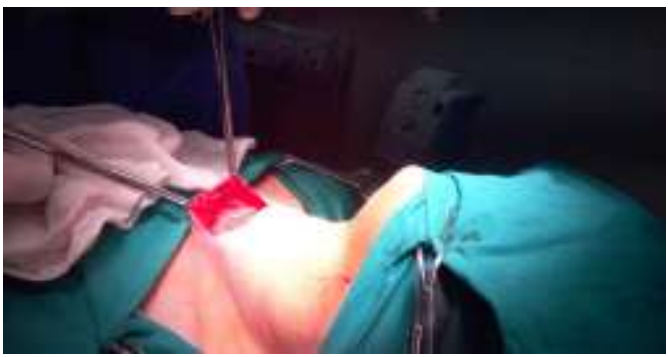

Fig (2) Elevation of inferior flab.

Two or three Allis clamps were placed on the fascia to retract the flap vertically.

- Thyroid Exploration: The midline was identified by palpating the prominence of the thyroid cartilage and the trachea and the midline raphe' were identified (pale, white) between the strap muscles. The cervical fascia was opened in the midline from the thyroid cartilage to the suprasternal notch to expose the full length of the strap muscles. The sternohyoid muscle and underlying sternothyroid muscle were also separated in the midline from the thyroid cartilage to the suprasternal notch until the thyroid gland was seen.

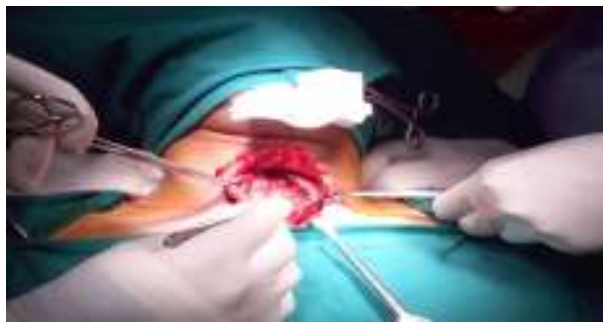

Fig (3) Opening of the strap muscles.

- Techniques of preservation of the superior parathyroid gland: The location of the superior parathyroid gland was very much consistent and was in the place of upper third of the thyroid gland (near the tubercle of Zuckerkandl at the level of the cricoid cartilage) and had direct contact with the thyroid capsule posteriorly. As the initial step, the focus of the dissection was to identify and preserve the superior parathyroid gland along with their vascular supply instead of identifying the RLN laterally in the paratracheal groove. Dissection was close to the true capsule, otherwise, the possible injury that might occur to superior parathyroid gland along with their blood supply.

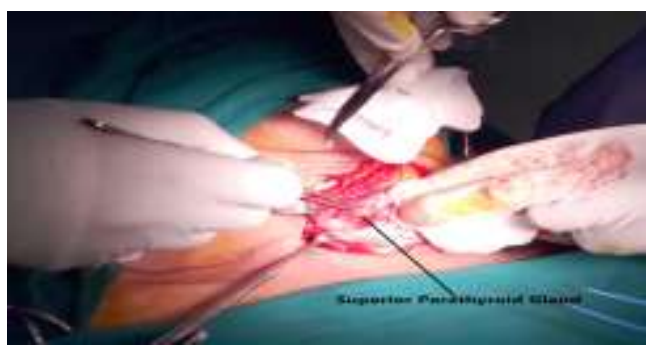

Fig (4) Preservation of the superior parathyroid gland.

- Techniques of preservation of the inferior parathyroid gland: Most of cases; the inferior parathyroid glands were found within $1 \mathrm{~cm}$ of where the recurrent laryngeal nerve crosses the inferior thyroid artery, so we used any of them as a guide to the other.

The inferior pole vessels were the blood supply to the inferior parathyroid gland and some to the superior parathyroid gland, so only the terminal branches that were directly entering the thyroid gland were divided.

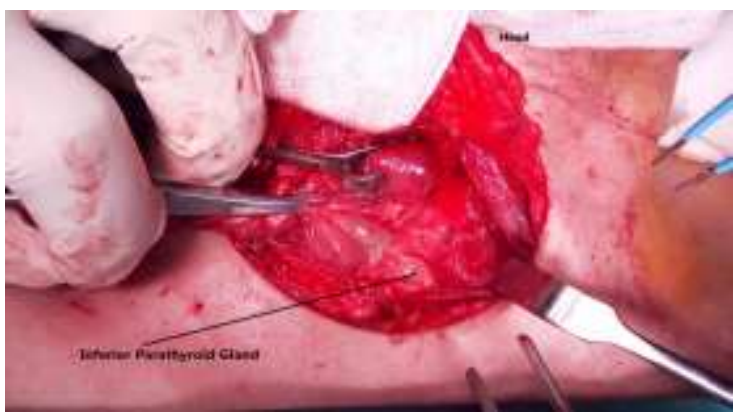

Fig (5) Dissection and Preservation of the inferior parathyroid gland

- Hemostasis and closure: Meticulous hemostasis was then assured after irrigating the space previously occupied by the thyroid gland; with saline to identify small bleeding points which were secured with bipolar diathermy.

Postoperative work up 
Routine follow up as any thyroid surgery monitoring blood pressure, pulse, temperature and drains. The presence and the type of symptoms of hypocalcaemia were registered twice a day from the day of surgery to postoperative day two which include numbness around the lips or the tips of the extremities and positive Chvostek's or Trousseau's signs were considered to be compatible with mild hypocalcaemia while the carpopedal spasm, convulsions and laryngospasm were considered to be associated with advanced hypocalcaemia.

- Post-operative sample collection: Parathyroid hormone level which was measured six hours postoperatively (normal range of PTH: 15- 65 $\mathrm{pg} / \mathrm{ml}$ ) Total serum calcium level which was measured six hours postoperatively (normal range of total calcium: 8.5-10.3 mg/dL).

\section{Results}

A prospective non-randomized study was conducted in the period between November 2018 and September 2019 in Benha university hospital, general surgery department. The study included 50 patients having thyroid disease for whom total thyroidectomy was done.

Table (1) In the study the mean preoperative serum calcium was $9.2 \pm 0.47 \mathrm{mg} / \mathrm{dL}$, the mean 6 hours post-operative serum calcium was $8.55 \pm 0.60 \mathrm{mg} / \mathrm{dL}$ In the study the mean preoperative serum parathyroid hormone was $42.0 \pm 8.54 \mathrm{pg} / \mathrm{ml}$ and the mean 6 hours postoperative parathyroid hormone was $31.54 \pm 13.29 \mathrm{pg} / \mathrm{ml}$.

Table (1) Comparison between preoperative and $6^{\text {th }}$ hr postoperative CA and PTH $(n=50)$.

\begin{tabular}{lccc}
\hline Ca & Preoperative & Postoperative & p \\
\hline Min. - Max. & $8.50-10.0$ & $6.80-9.70$ & $<0.001^{*}$ \\
Mean I SD. & $9.20 \pm 0.47$ & $8.55 \pm 0.60$ & \\
PTH & & & \\
Min. - Max. & $22.0-62.0$ & $2.0-48.0$ & $<0.001^{*}$ \\
Mean + SD. & $42.0 \pm 8.54$ & $31.54 \pm 13.29$ & \\
\hline
\end{tabular}

Table (2) The normocalcaemic patients were 38 and the hypocalcaemic patients were 12 patients. The mean age of normocalcaemic group was $49.32 \pm 10.47$ and the mean age of hypocalcaemic group was $52.67 \pm$ $6.43(\mathrm{P}=0.193)$. The number of male patients in normocalcaemic group was 10 patients and no patients in hypocalcaemic group were males, the number of female patients in normocalcaemic group was 28 patients and in hypocalcaemic group was 12 patients $(\mathrm{P}$ $=0.092$ ). From these findings, there was no statistically significant difference between normocalcaemic and hypocalcaemic groups as regards demographic findings.

Table (2) Comparison between the two studied groups according to demographic data.

\begin{tabular}{|c|c|c|c|c|c|}
\hline & \multicolumn{2}{|c|}{$\begin{array}{l}\text { Normocalcaemia } \\
(\mathbf{n}=\mathbf{3 8})\end{array}$} & \multicolumn{2}{|c|}{$\begin{array}{c}\text { Hypocalcaemia } \\
(\mathrm{n}=12)\end{array}$} & \multirow[t]{2}{*}{$\mathbf{p}$} \\
\hline & No. & $\%$ & No. & $\%$ & \\
\hline \multicolumn{6}{|l|}{ Sex } \\
\hline Male & 10 & 26.3 & 0 & 0.0 & ${ }^{F E} \mathbf{p}=$ \\
\hline Female & 28 & 73.7 & 12 & 100.0 & 0.092 \\
\hline \multicolumn{6}{|l|}{ Age } \\
\hline Min. - Max. & \multirow{2}{*}{\multicolumn{2}{|c|}{$\begin{array}{c}28.0-62.0 \\
49.32 \pm 10.47\end{array}$}} & \multirow{2}{*}{\multicolumn{2}{|c|}{$\begin{array}{c}43.0-61.0 \\
52.67 \pm 6.43\end{array}$}} & 0.193 \\
\hline Mean \pm SD. & & & & & \\
\hline
\end{tabular}

Table (3) In normocalcaemic group; the mean preoperative serum calcium was $9.22 \pm 0.43 \mathrm{mg} / \mathrm{dL}$ while hypocalcaemic group it was $9.17 \pm 0.59 \mathrm{mg} / \mathrm{dL}$. In normocalcaemic group; the mean 6 hours postoperative serum calcium was $8.79 \pm 0.38 \mathrm{mg} / \mathrm{dL}$, while in hypocalcaemic group it was $7.78 \pm 0.52 \mathrm{mg} / \mathrm{dL}(\mathrm{P}<$ 0.001). In normocalcaemic group; the mean preoperative serum parathyroid hormone was $43.95 \pm$ $7.01 \mathrm{pg} / \mathrm{ml}$, while in hypocalcaemic group; it was 35.83 $\pm 10.24 \mathrm{pg} / \mathrm{ml}$. In normocalcaemic group the mean postoperative serum parathyroid hormone was $37.13 \pm$ $8.57 \mathrm{pg} / \mathrm{ml}$, while in hypocalcaemic group it was 13.83 $\pm 9.49 \mathrm{pg} / \mathrm{ml}(\mathrm{P}<\quad 0.001)$. There was statistically significant difference between normocalcaemic and hypocalcaemic groups as regards the mean serum calcium levels 6 hours postoperatively and the mean parathyroid hormone level 6 hours postoperatively. 
Table (3) Comparison between the two studied groups according to Ca and PTH.

\begin{tabular}{|c|c|c|c|}
\hline & $\begin{array}{l}\text { Normocalcaemia } \\
\quad(n=38)\end{array}$ & $\begin{array}{c}\text { Hypocalcaemia } \\
(n=12)\end{array}$ & $\mathbf{p}$ \\
\hline \multicolumn{4}{|l|}{ Preoperative ca level } \\
\hline Min. - Max. & $8.5-9.9$ & $8.5-10.0$ & \multirow[t]{2}{*}{0.794} \\
\hline Mean \pm SD & $9.22 \pm 0.43$ & $9.17 \pm 0.59$ & \\
\hline 6 hr. Postoperative ca level & & & \\
\hline Min. - Max. & $8.5-9.70$ & $6.8-8.2$ & \multirow[t]{2}{*}{$<0.001^{*}$} \\
\hline Mean \pm SD & $8.79 \pm 0.38$ & $7.78 \pm 0.52$ & \\
\hline Preoperative PTH level & & & \\
\hline Min. - Max. & $34.0-62.0$ & $22.0-49.0$ & \multirow[t]{2}{*}{$0.022^{*}$} \\
\hline $\begin{array}{l}\text { Mean } \pm \text { SD. } \\
6 \text { hr. Postoperative PTH level }\end{array}$ & $43.95 \pm 7.01$ & $35.83 \pm 10.24$ & \\
\hline Min. - Max. & $15.0-48.0$ & $2.0-29.0$ & \multirow[t]{2}{*}{$<0.001^{*}$} \\
\hline $\begin{array}{l}\text { Mean } \pm \text { SD. } \\
p_{1}\end{array}$ & $37.13 \pm 8.57$ & $13.83 \pm 9.49$ & \\
\hline
\end{tabular}

Table (4) In normocalcaemic patients, relative decline of serum calcium was $4.52 \% \quad 6$ hours postoperative. In hypocalcaemic patients relative decline of serum calcium was $14.71 \% 6$ hours postoperative $(\mathrm{p}<0.001)$. Relative decline of parathyroid hormone in normocacaemic patients was $12.88 \%$ and in hypocalcaemic patients it was $65.33 \%, 6$ hours postoperative $(\mathrm{p}<0.001)$.

Table (4) Comparison between the two studied groups according to $\%$ of change.

\begin{tabular}{lccc}
\hline \% of change & $\begin{array}{c}\text { Normocalcaemia } \\
(\mathbf{n}=\mathbf{3 8})\end{array}$ & $\begin{array}{c}\text { Hypocalcaemia } \\
(\mathbf{n}=\mathbf{1 2})\end{array}$ & $\mathbf{p}$ \\
\hline Ca & & & \\
Min. - Max. & $0.0-14.14$ & $3.53-27.66$ & $<0.001^{*}$ \\
Mean \pm SD. & $4.52 \pm 4.17$ & $14.71 \pm 8.56$ & \\
PTH & & & \\
Min. - Max. & $-5.88-67.74$ & $35.90-35.90$ & $<0.001^{*}$ \\
Mean \pm SD. & $12.88 \pm 23.07$ & $65.33 \pm 18.72$ & \\
\hline
\end{tabular}

Table (5) In analysis of the study relevant to PTH decline, we found that with a threshold of parathyroid hormone decline ( $6 \mathrm{~h}$ postoperative) of $62 \%$, sensitivity and specificity values were respectively $75.0 \%$ and
$84.21 \%, 60 \%$ PPV and $91.43 \%$ NPV that shows PTH $\%$ of reduction was considered better negative than positive predictor for hypocalcaemia with higher specificity for hypocalcaemia.

Table (5) Agreement (sensitivity, specificity) for PTH \% of reduction to predicate hypocalcaemia patients.

\begin{tabular}{|c|c|c|c|c|c|c|c|c|c|}
\hline & \multirow[t]{2}{*}{$\mathbf{A U C}$} & \multirow[t]{2}{*}{$\mathbf{p}$} & \multicolumn{2}{|c|}{ 95\% C.I } & \multirow{2}{*}{$\begin{array}{l}\text { Cut } \\
\text { off }\end{array}$} & \multirow[t]{2}{*}{ Sensitivity } & \multirow[t]{2}{*}{ Specificity } & \multirow[t]{2}{*}{ PPV } & \multirow[t]{2}{*}{ NPV } \\
\hline & & & $\mathbf{L L}$ & UL & & & & & \\
\hline $\begin{array}{l}\text { PTH \% of } \\
\text { reduction }\end{array}$ & 0.925 & $<0.001^{*}$ & 0.855 & 0.996 & $>62$ & 75.0 & 84.21 & 60.0 & 91.43 \\
\hline
\end{tabular}

\section{Discussion}

In the study there was no statistically significant difference between normocalcaemic and hypocalcaemic groups as regards age and sex, which was similar to [7], while [8] showed that the incidence of hypocalcaemia is more in Younger and female patients and this can be explained by pre and post-menopausal hormonal factors compared to the men, while [9] found that The risk for postoperative hypocalcemia was increased 20 -fold for patients older than 50 years, [10] found that the elderly patients were riskier in the development of hypocalcaemia.
In agreement with these results [11], reported that significant statistical results were not found on postoperative hypocalcemia in terms of sex.

In the study results demonstrated that the overall incidence of post-thyroidectomy hypocalcemia was $24 \%$, this was more than the incidence of hypocalcaemia reported by [7], where the overall prevalence rate of post-thyroidectomy hypocalcemia was $11.98 \%$ while in [8] the incidence was $9.0 \%$, while (12) the incidence were $42 \%$ and $30.8 \%$ respectivelly. 
In the studied cases the mean preoperative serum calcium was $9.2 \mathrm{mg} / \mathrm{dL}$, the mean 6 hours postoperative serum calcium was $8.55 \mathrm{mg} / \mathrm{dl}(\mathrm{P}<0.001)$.

As regard to the mean preoperative serum calcium in normocalcemic group was $9.22 \mathrm{mg} / \mathrm{dL}$ while hypocalcemic group it was $9.17 \mathrm{mg} / \mathrm{dL}$. In normocalcemic group; the mean 6 hours postoperative serum calcium was $8.79 \mathrm{mg} / \mathrm{dL}$, while in hypocalcemic group it was $7.3 \mathrm{mg} / \mathrm{dL}(\mathrm{P}<0.001)$.

So, there was a high statistically significant difference as regard serum calcium level in normocalcemic and hypocalcemic groups postoperative $(\mathrm{P}<0.001)$, in agreement with these results [13] found a statistical difference as regard serum calcium level in normocalcemic and hypocalcemic groups postoperative.

In the study, the normocalcemic group; the mean preoperative serum parathyroid hormone was 43.95 $\mathrm{pg} / \mathrm{ml}$, while in hypocalcemic group; it was 35.83 $\mathrm{pg} / \mathrm{ml}$. The normocalcemic group the mean postoperative serum parathyroid hormone was 37.13 $\mathrm{pg} / \mathrm{ml}$, while in hypocalcemic group it was $13.83 \mathrm{pg} / \mathrm{ml}$ $(\mathrm{P}<0.001)$. There was high statistically significant difference between normocalcemic and hypocalcaemic groups as regards the mean serum parathyroid hormone level 6 hours postoperatively.

Regarding [12] the normocalcemic group; the mean preoperative serum parathyroid hormone was 63.3 $\mathrm{pg} / \mathrm{ml}$, while in hypocalcemic group; it was $76.8 \mathrm{pg} / \mathrm{ml}$. In normocalcemic group the mean postoperative serum parathyroid hormone was $32.2 \mathrm{pg} / \mathrm{ml}$, while in hypocalcemic group it was $14.9 \mathrm{pg} / \mathrm{ml}$

In analysis of the study relevant to PTH decline, we found that with a threshold of parathyroid hormone decline (6 hours postoperative) of $62 \%$, sensitivity and specificity values were respectively $75.0 \%$ and 84.21 $\%, 60 \%$ PPV and $91.43 \%$ NPV that shows PTH $\%$ of reduction was considered better negative than positive predictor for hypocalcemia with higher specificity for hypocalcemia.

On the other hand, several investigators used PTH measurement and not the percentage of drop like [13] who found that 15 out of 16 patients who developed post thyroidectomy hypocalcaemia had 4- and 6-hour postoperative PTH levels of less than $10 \mathrm{pg} / \mathrm{ml}$ with a $100 \%$ specificity, $94 \%$ sensitivity, and $98 \%$ overall accuracy.

Similarly, [14] demonstrated sensitivity, specificity and positive predictive value of $70.7 \%, 92.6 \%$, and $71.6 \%$, respectively, for low PTH levels (<10 ng/l) $4 \mathrm{~h}$ after surgery in predicting postoperative hypocalcaemia $(<2.0 \mathrm{mmol} / \mathrm{l})$. This led to the inclusion of the routine measurement of PTH postoperatively in the Australian Endocrine Surgeons Guidelines, in 2007 for patients undergoing total thyroidectomy.

Others like [13] found that combining information from postresection PTH levels $(\leq 18 \mathrm{pg} / \mathrm{mL})$ and PTH decline greater than $62.5 \%$ as cut off gives $93.3 \%$ sensitivity, $83.3 \%$ specificity, $77.8 \%$ ppv \& $95.2 \%$ npv.

While [12] found that $6 \mathrm{hrs}$ postop PTH decline percentage greater than $44 \%$ could be considered safe for early discharge, with sensitivity of $100 \%$, specificity of $53.8 \%$, ppv $64.7 \%$ and npv of $100 \%$.

This was corroborated by the work of [15] who found that PTH value below 12.1ng/L predicted which patient had a greater chance of developing symptoms of hypocalcaemia with $93.7 \%$ sensitivity and $91.6 \%$ specificity. PTH drop of $73.5 \%$ also effectively predicted symptoms of hypocalcaemia among patients who underwent total thyroidectomy with $91.6 \%$ sensitivity and $87.5 \%$ specificity.

It has been well-established that the most common form of transient or permanent hypoparathyroidism was postsurgical. Moreover, neck exploration for thyroid cancer, Graves' disease, large multinodular goiter, together with poor surgeon's experience, vitamin D deficiency, and age and rate of PTH decline may represent important factors that will negatively affect the calcium and phosphate balance.

\section{Conclusion \& Recommendations}

Post thyroidectomy hypocalcaemia is one of the most common complications following total thyroidectomy. Early identification and treatment of patients at high risk of symptomatic hypocalcaemia is the cornerstone of dealing with thyroidectomy as a oneday surgery. Serial calcium measurement once used as the basis of identification of post thyroidectomy hypocalcaemia has now been widely replaced by PTH measurement. The perioperative PTH measurement can monitor parathyroid function and identify patients at risk of clinically significant hypocalcaemia much earlier and more accurately than serum calcium alone monitoring. In the study, a drop in postoperative PTH levels by more than $62 \%$ may serve as a sensitive and specific indicator of hypocalcemia with high overall accuracy and this will help in selecting patients for early discharge after total thyroidectomy.

\section{References}

[1] S. N. Karamanakos, k. B. Markou,K. Panagopoulos, Complications and risk factors related to the extent of surgery in thyroidectomy. Results from 2,043 procedures. Hormones.; Vol. 9(4), pp.318-325, 2010.

[2] T. W. Ho, A. A. Shaheen, E. Dixon, Utilization of thyroidectomy for benign disease in the United States: a 15-year population-based study. The American surgery j.; Vol. 201(5), pp.570-574, 2010.

[3] H. M. Mehanna,A. Jain, H. Randeva,Postoperative hypocalcemia - the difference a definition makes. Head \& Neck: J for the Sciences and Specialties of the Head and Neck,Vol. 32(3),pp.279-283, 2010.

[4] J. H. Kim, M. K. Chung, M.K. Reliable early prediction for different types of post-thyroidectomy hypocalcemia. Clinical and experimental otorhinolaryngology, Vol. 4(2), pp.95, 2011.

[5] M. Khan,S. Waguespack, M. Hu, Medical management of postsurgical 
hypoparathyroidism. Endocrine Practice, Vol. 17(Supplement 1), pp.18-25, 2011.

[6] A. Sanabria,L. C. Dominguez,V. Vega, Routine postoperative administration of vitamin $\mathrm{D}$ and calcium after total thyroidectomy: a metaanalysis. International $\mathbf{J}$ of Surgery, Vol. 9(1), pp.46-51, 2011.

[7] M. F. I. Celzo, M. A. L. Picorro, L. R. A. Alcances, Clinical predictors of post-thyroidectomy hypocalcemia: A retrospective review. Philipp J Intern Med, Vol. 43(6), pp.331-41, 2005.

[8] R. L. Baldassarre, D. C. Chang,K. T. Brumund, Predictor of hypocalcemia after thyroidectomy: results from the nationwide inpatient sample. ISRN surgery, Vol. 23(5),pp.1-7, 2012.

[9] S. Tolone,R. Roberto,G. del Genio, The impact of age and oral calcium and vitamin D supplements on postoperative hypocalcemia after total thyroidectomy. A prospective study. BMC surgery, Vol. 13(S2), pp.S11, 2012.

[10] A. Weiss, R. P. Parina,J. A. Tang, Outcomes of thyroidectomy from a large California state database. The American J of Surgery,Vol. 210(6), pp.1170-1177, 2015.
[11] O. Edafe,R.Antakia, N. Laskar, Systematic review and meta-analysis of predictors of postthyroidectomy hypocalcaemia. British $\mathrm{J}$ of Surgery, Vol. 101(4), pp.307-320, 2015.

[12]D. B. Chapman, C. C. French, X. Leng, Parathyroid hormone early percent change: an individualized approach to predict postthyroidectomy hypocalcemia. American $\mathrm{J}$ of otolaryngology, Vol. 33(2), pp.216-220, 2014.

[13]C. P. Lombardi,M. Raffaelli, P. Princi, Early prediction of post thyroidectomy hypocalcemia by one single iPTH measurement. Surgery, Vol. 136(6), pp.1236-1241, 2002.

[14]S. Grodski,J. Serpell, Evidence for the role of perioperative PTH measurement after total thyroidectomy as a predictor of hypocalcemia. World J of surgery, Vol. 32(7), pp.1367-1373, 2008.

[15]F. A. B. Vanderlei, J. G. H. Vieira, F. C. Hojaij, Parathyroid hormone: an early predictor of symptomatic hypocalcemia after total thyroidectomy. Arquivos Brasileiros de Endocrinologia \& Metabologia,Vol. 56(3), pp.168$172,2012$. 